\title{
Laudation for Professor RNDr. Pavel P. Povinec, DrSc: 2017 Hevesy Medal Award recipient
}

\author{
A. Chatt $^{1}$ \\ Published online: 10 March 2018 \\ (C) Akadémiai Kiadó, Budapest, Hungary 2018
}

Pavel Povinec was born in Ochodnica, Slovakia. He received his $\mathrm{PhD}$ on a thesis entitled ${ }^{\prime 3} \mathrm{H}$ and ${ }^{14} \mathrm{C}$ low-level counting by proportional counters" in 1973 from Comenius University in Bratislava, Slovakia (formerly Czechoslovakia). He started his career as an Assistant Professor of Physics at Comenius University in 1966, became an Associate Professor in 1978, and a Full Professor in 1984. He served as the Head of the Department of Nuclear Physics there during 1981-1992. He was the Head of the International Atomic Energy Agency's Radiometric Laboratory in Monaco during 1993-2004, and Head of the Centre for Nuclear and Accelerator Technologies (CENTA) of the Comenius University from 2013.

At the beginning of his career at the Comenius University during 1966-1993, Professor Povinec was involved in low-level radioactivity measurements by designing new types of proportional counters (the Povinec multi-element counter), by developing methods for gas fillings, and for simultaneous measurement of ${ }^{3} \mathrm{H}$ and ${ }^{14} \mathrm{C}$ (the Povinec method). He initiated almost 50-year long continuous ${ }^{14} \mathrm{C}$ measurements in the atmosphere, which are the second longest in the world and which helped to study fossil fuel impacts on the atmosphere. During the same period Professor Povinec was involved in nuclear physics experiments investigating rare particle interaction processes and radioactive decays of nuclei with very long halflives.

During his stay in the IAEA's Marine Environment Laboratories in Monaco he continued to work on radiochemical separations of natural and anthropogenic radionuclides, namely ${ }^{3} \mathrm{H},{ }^{14} \mathrm{C},{ }^{90} \mathrm{Sr},{ }^{129} \mathrm{I},{ }^{137} \mathrm{Cs},{ }^{210} \mathrm{Po}$, Ra, $\mathrm{Th}, \mathrm{U}, \mathrm{Np}, \mathrm{Pu}, \mathrm{Am}$, and $\mathrm{Cm}$ isotopes, and on the development of AMS and ICP-MS analysis methods, which

\section{A. Chatt}

chatt@dal.ca

1 Department of Chemistry, Trace Analysis Research Centre, Dalhousie University, 6274 Coburg Road, Room 212, P.O. Box 15000, Halifax, NS B3H 4R2, Canada improved detection limits by several orders of magnitude, and some of them were applied in environmental studies for the first time. A specific radioanalytical technology he developed at IAEA Monaco was an in situ underwater gamma-spectrometer which is advantageous because not only of a great simplification of radioanalytical procedures but also for studies of temporal and spatial variations of radionuclides in the aquatic environment, including satellite data transmission. It was deployed, e.g., in the Mediterranean, Kara and Irish seas, in Mururoa Lagoon, and other places.

After returning to his home university in 2005 Professor Povinec has been continuing further development of radioanalytical methods. He has also been engaged in development of INAA methods for ultra low-level analysis of long-lived radionuclides $\left({ }^{40} \mathrm{~K}\right.$, $\mathrm{U}$ and $\left.\mathrm{Th}\right)$ in materials for underground experiments and studies of rare nuclear events, such as the search for $2 v \beta \beta$ and $0 v \beta \beta$ decays. His main achievement at the home university has been, however, the establishment of the CENTA (Centre for Nuclear and Accelerator Technologies), comprising of a 3-MV tandem accelerator, and focusing on AMS and on IBA including PIXE, PIGE, RBS and NRA.

Professor Povinec published over 400 papers, authored/ co-authored 2 books, 5 book chapters, and 33 reports. He presented 48 invited and 154 contributed papers at conferences, workshops and seminars. His book co-authored with K. Hirose and M. Aoyama entitled "Fukushima Accident: Radioactivity Impact on the Environment", Elsevier, New York, 2013, has received the 2014 PROSE Award of American Science Publishers as the best book in Environmental Sciences. It also won the 2014 Award of the Slovak Literary Foundation for the best Scientific Book. At the Comenius University, he established undergraduate and graduate courses on Nuclear physics and on Environmental Physics; he taught 10 courses and 5 seminars, and supervised $23 \mathrm{PhD}$ students, $21 \mathrm{MSc}$ students, 4 postdoctoral fellows, 5 visiting scientists and 15 trainees. Professor Povinec wrote 3 textbooks for students. He is the editor, 


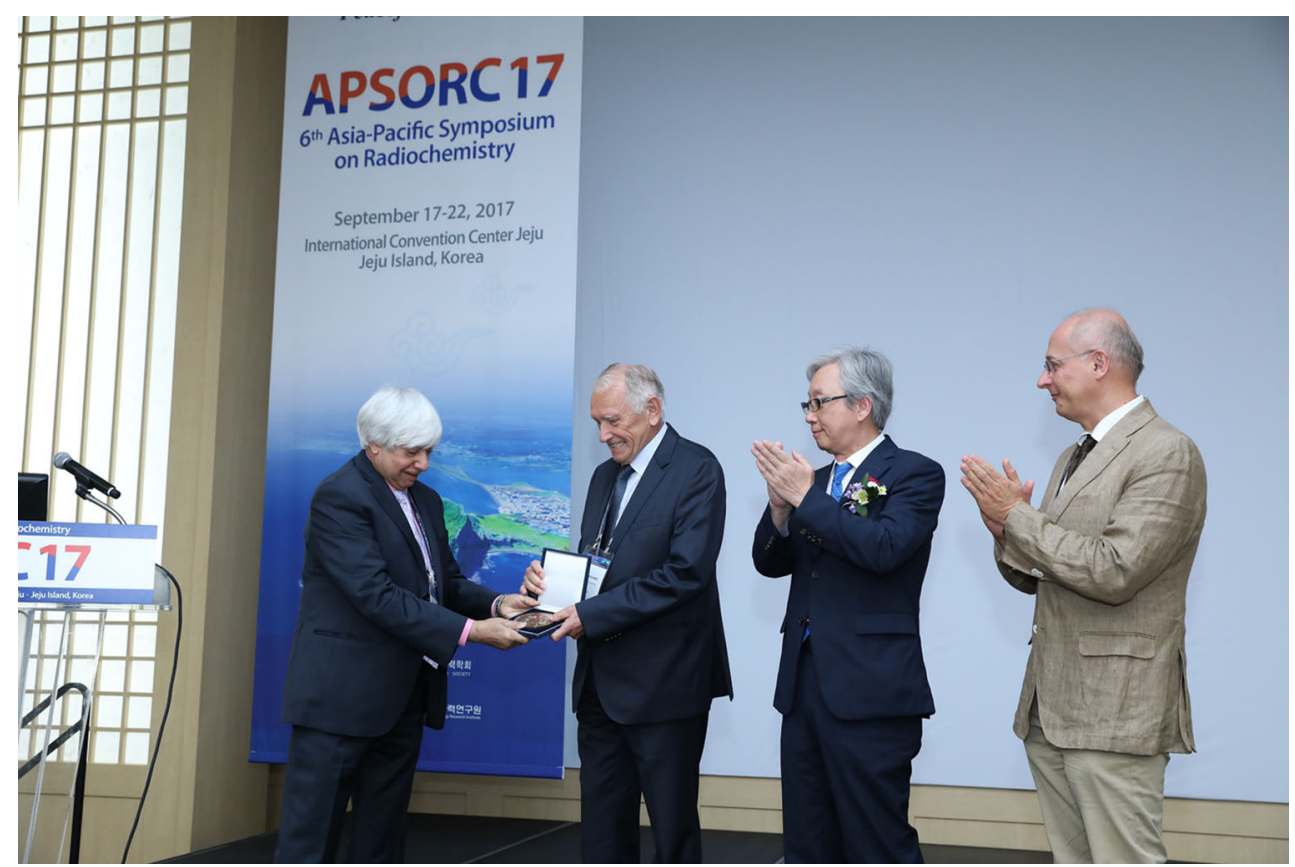

Fig. 1 From left to right: Prof. Amares Chatt, Prof. Pavel P. Povinec, Dr. Kwang Yong Jee, and Dr. Zsolt Revay

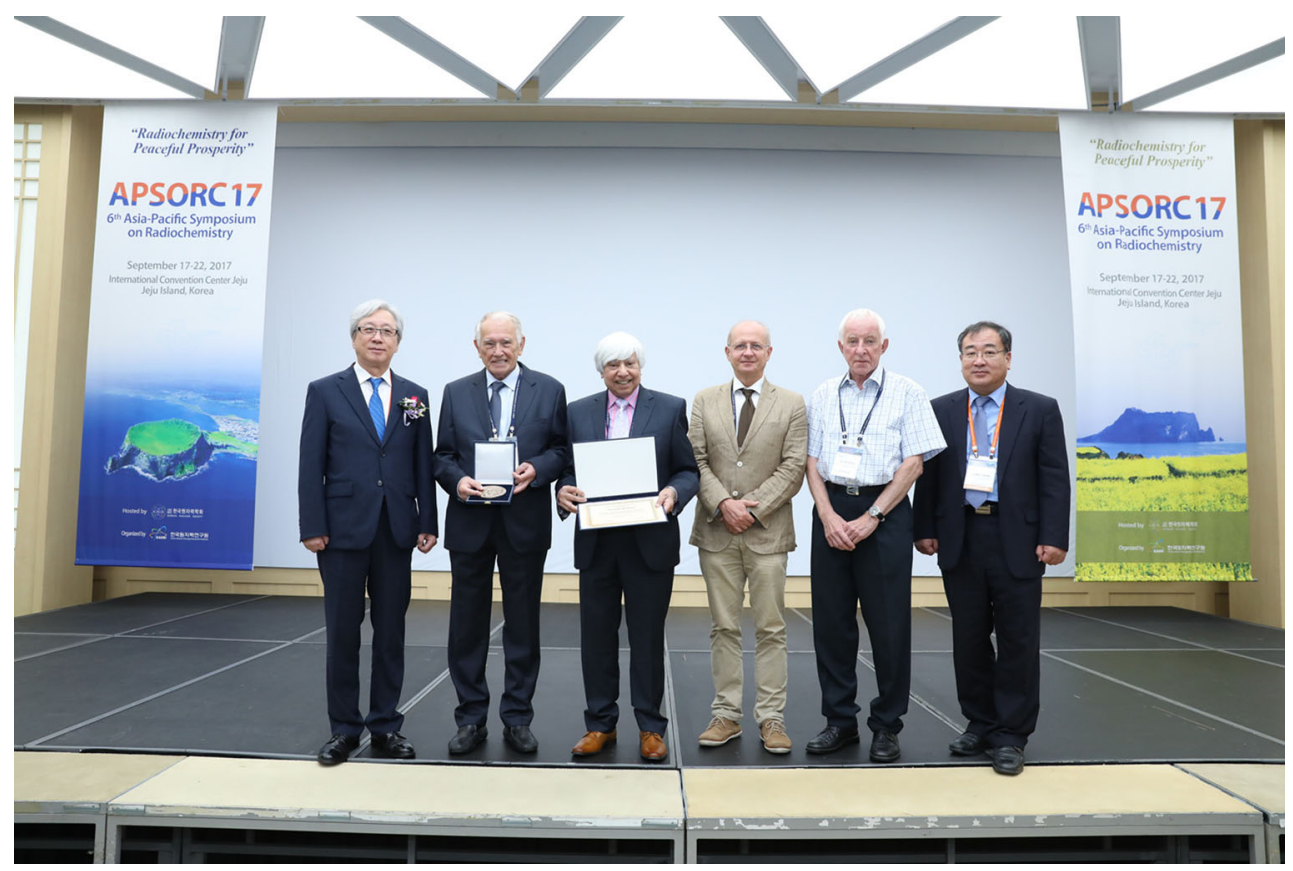

Fig. 2 From left to right: Dr. Kwang Yong Jee, Prof. Pavel P. Povinec, Prof. Amares Chatt, Dr. Zsolt Revay, Prof. Jan Kucera, and Dr. Jei-Won Yeon

associate editor, conference proceeding editor of several journals.

He has received numerous awards including 2016 Slovak Award "Best Scientist of the Year", 2016 Award of the Slovak Literary Foundation for the best citation record, 2012 and 2017 Medal and Award of the Slovak Physical Society, 2012 Commemorative Medal and 2007 Gold
Medal of Comenius University. He was a Member of the IAEA team of the 2005 Nobel Peace Prize.

It is indeed a pleasure to honor Professor RNDr. Pavel P. Povinec, DrSc with the Hevesy Medal Award 2017 (HMA17) in recognition of his work in the development of ultrasensitive radioanalytical technologies and their applications in large-scale environmental research studies, 


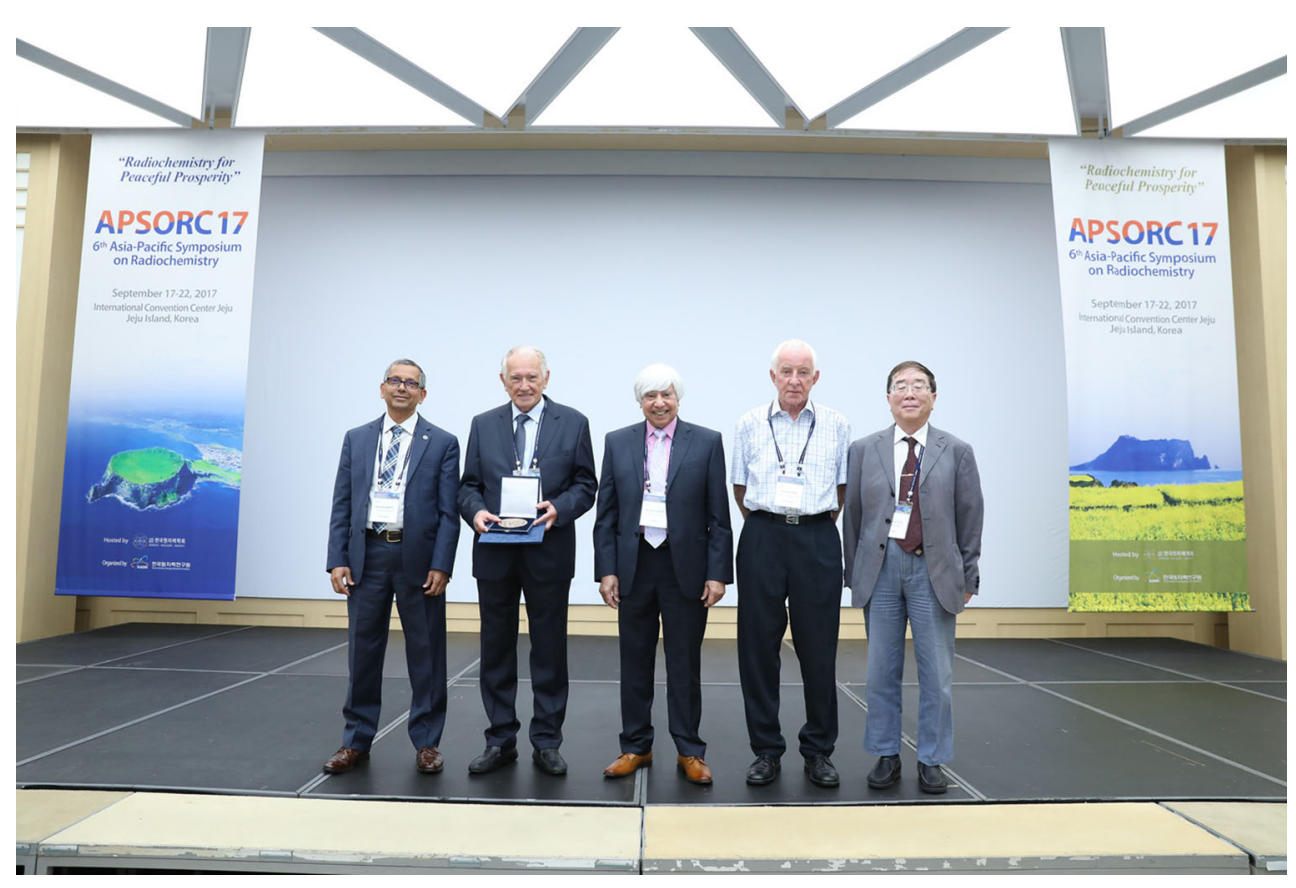

Fig. 3 From left to right (year of the award): Prof. Kattesh V. Katti (2015), Prof. Pavel P. Povinec (2017), Prof. Amares Chatt (2001), Prof. Jan Kučera (2006), and Prof. Zhifang Chai (2005)

investigation of rare nuclear processes, and development of high-sensitivity accelerator technologies for isotope analysis.

Professor Povinec was nominated by Professor Dr. Jan Kucera (Czech Academy of Sciences, Czech Republic), and co-sponsored by Professor Eiliv Steinnes (Norwegian University of Science and Technology, Norway) and Associate Professor Dr. Ir. Peter Bode (Delft University of Technology, The Netherlands).

The Hevesy Medal Award Selection Panel 2017 (HMASP-17) consisted of Professor Amares Chatt (Dalhousie University, Canada, also Chair of JRNC Board of the Hevesy Award and Chair of HMASP-17), Professor Tibor Braun (JRNC Board of the Hevesy Award), Professor Zhifang Chai (Chinese Academy of Sciences, China), Professor Yong Hee Chung (Hallym University, Korea, also representing APSORC 17), Professor Sue Clark
(Washington State University, USA), Dr. Yuichiro Nagame (Japan Atomic Energy Agency, Japan), Professor Syed Qaim (Forschungszentrum Juelich GmbH, Germany), Dr. Zsolt Revay (Technische Universität München, Germany, also JRNC Board of the Hevesy Award), and Dr. Rolf Zeisler (National Institute of Standards and Technology, USA). In accordance with the rules of the Award, a secret vote was conducted.

The Hevesy Medal and a Scroll were presented to Professor Povinec at the 6th Asia-Pacific Symposium on Radiochemistry (APSORC 17) held in Jeju Island, Korea during 2017 September 17-22 (Figs. 1, 2).

Several of the past Hevesy Medal Awardees attended APSORC 17 and were present at the Hevesy Medal Award session (Fig. 3).

All photos are courtesy of the APSORC 17 Organizing Committee. 